\title{
Introduction: The Continuing Search for Deliberation and Participation in China
}

\author{
Beibei Tang • John S. Dryzek
}

Published online: 25 February 2014

C) Journal of Chinese Political Science/Association of Chinese Political Studies 2014

Deliberative democracy has deep roots in human history, and something like deliberation can be found in many sorts of societies throughout the world. The enthusiasm for deliberative democracy that began in the 1990s stressed its application within established liberal democracies, spanning structured deliberative forums, informal citizen deliberations in the public sphere, and different stages of public policy formation. ${ }^{1}$

However and wherever it was achieved, the core claim was that legitimate collective decision making and policy making depends crucially on the right, opportunity, and capacity of citizens subject to those decisions to be able to participate in meaningful and influential deliberation about the content of those decisions. Given that its conception of democracy is - in the words of Chambers - "talk-centric" rather than "votecentric", [4] it soon became apparent that the "deliberative turn" in thinking about politics should be able to reach settings such as global politics and societies where elections are not central or even present. Village elections notwithstanding, one such society is contemporary China, [5] and so our topic in this special issue is to take stock of developments in the application to China of deliberative thinking, what is being achieved in practice, and what this says about prospects for the democratization of China.

Although historically the theory of deliberative democracy was developed in Western liberal democracies, to ask whether deliberative democracy can travel to other settings, beyond developed Western liberal democracies, is not the right question. It is better to investigate instead the degree to which deliberative practices that can form a basis for democracy can be found in the traditions and practices of particular societies and systems. Democratization understood as the building of deliberative capacity can

\footnotetext{
${ }^{1}$ For example: [1-3]

B. Tang $(\bowtie)$

Department of Political \& Social Change, College of Asia and the Pacific, Australian National University, Canberra, ACT 0200, Australia

e-mail: beibei.tang@anu.edu.au
}

J. S. Dryzek

ANZSOG Institute for Governance, University of Canberra, Canberra, ACT 2601, Australia e-mail: john.dryzek@canberra.edu.au 
be framed in such a way that allows that capacity to be sought in very different ways in different societies.

After more than three decades of China's economic reform, the party-state has shown no signs of weakening its control of political power. But the Chinese Communist Party has repeatedly highlighted the need for democratic reforms - though their actual content remains uncertain. Most recently, the Party emphasized that "power must be supervised by the people and exercised transparently" and called for "enriching democratic forms to show the advantages of China's socialist political system." ${ }^{2}$ What matters for the party-state to retain regime legitimacy is governance performance, so there is little interest in democratic reform for its own sake. In this light, deliberative capacity building is different from most existing debates on democratization trajectories in China, which aim to speculate whether and when China as a whole will become democratic, and through what kind of participation. Instead its emphasis is on the ways in which deliberation can be practiced in particular locations at different levels of governance to enhance participation and promote democracy.

Despite continuing popular support for the central leadership, ${ }^{3}$ governance in China - particularly local governance - in the past two decades has been facing growing public resistance due to seemingly illegitimate decision-making and poor policy implementation. The functional need to pursue social stability and governance legitimacy has become the main rationale for the authoritarian regime to adopt deliberative politics regarding practical governance matters. $[12,13]$ In recent years, policy consultations using deliberative approaches have been more frequently observed at local levels, to help to resolve conflicts, improve governmental performance, and generally promote legitimacy in governance. The wide range of local innovations includes participatory budgeting, public hearings, as well as village assemblies and consultative meetings. [14-16] The influences of these participatory innovations have shown that to a certain degree, elite decisions and policy making in China could respond to persuasive influences and arguments generated among citizen participants. Deliberative and participatory innovations have revealed a paradoxical but apparently practical governance strategy in reform-era China: deliberative policy consultation under an authoritarian regime. The paper in this special issue by Korolev on health care reform shows that a degree of deliberation can now occur on national policy issues. This particular case featured participation mainly by experts of various sorts, academics, and think tanks - so while more inclusive than traditional national policy making, it is still somewhat limited in the range of participants it encompassed.

The development of deliberative policy consultation in China does however remain partial and uneven. It remains unclear whether the piecemeal innovations we observe potentially point to systemic transformation-perhaps even what He and Warren call "deliberation-led democratization" [17] - that can be contrasted with the standard approach in democratization studies - especially in the United States - that sees democracy as coming in a well-defined package comprising competitive elections, constitutionalism, and a standard set of human rights, whose adoption comes in some clear moment of transition accompanying the breakdown of an authoritarian system. Deliberation-led democratization would, it seems, also require the development of a

\footnotetext{
${ }^{2}$ See [6]

${ }^{3}$ See for example, $[7-11]$
} 
multi-faceted and critical public sphere, rather than isolated innovations. On the other hand, it could be that these innovations simply bolster the legitimacy and authority of the party-state. What He and Warren call "authoritarian deliberation" constitutes adaptation on the part of the party-state to the variety of forces unleashed by rapid economic development. Deliberative and participatory innovations can therefore enable officials to become better informed about effects of policies that might otherwise remain hidden. It is also possible that instances of corruption may be illuminated by deliberative public participation. Yet deliberation will remain authoritarian so long as it occurs only within well-defined limits set by the party-state, however open participation and discussion in particular forums might be. To the extent that deliberative and participatory innovations do reinforce state legitimacy and authority, promoters of the standard Western model of democratization would become very uneasy indeed. At any rate, it does appear that political systems that are far from any "transition" can nevertheless develop deliberative capacity. For Fung this capacity can be sought to the extent that there are opportunities for collective public judgment, for communication of this judgment to the government, and for "the public to sanction public officials and call them to account". [18]

The papers in this special issue are therefore designed to investigate how deliberative and participatory innovations and developments in China contribute to the interplay of state and society. The idea is to grasp the essence of new characteristics and the unique trajectory of China's institutional adaptation, so as to enhance our understanding of governance and citizen participation in the context of dynamic transformation of a populous developing and socialist market economy. It is important to reflect upon what myriad experiments in deliberation and participation add up to-not just in the pages of an academic journal, but also in the political system itself. This is what Thompson calls "meta-deliberation", which means deliberation about how different deliberative and participatory practices can and should be organized. [19] Deliberative democratization on any significant scale would surely have to involve this kind of reflexive capacity for self-examination and self-transformation. Is there any such capacity in China? The 2005 White Paper issued by the Chinese government "Building of Political Democracy in China" 4 does perhaps contain intimations of such a capacity. This paper gives public interest arguments for non-liberal and non-competitive approaches to democracy in China - although it also contains a statement of some very significant constraints: Party leadership, socialist unity, social stability, and state dignity. But any more meaningful meta-deliberative capacity would need to involve a broader critical public sphere.

This special issue is of theoretical and empirical significance for three further reasons. First, it takes advantage of insights generated by the deliberative systems approach, now one of the most prominent research agendas in the study of deliberative democracy. [20] A deliberative system involves differentiated yet connected sites and practices that can be interpreted in light of the core normative commitments of deliberative democracy. The relevant sites include the institutions of the state, designed deliberative forums, the larger public sphere-including the media and internet activity — and public hearings, even discussion in informal settings. Aside from examining what occurs in particular locations, it is important to look at transmission and accountability mechanisms between different sites: transmission meaning communication of

$\overline{{ }^{4} \text { Online at http://english.people.com.cn/whitepaper/democracy/democracy.html }}$ 
public judgment to those exercising public authority; accountability meaning that those in power need to answer to a broader public in terms that involve meaningful communication. [21] Most existing studies of deliberative governance in China have yet to grasp this systemic aspect because they have focused on isolated deliberative practices. It is important to move beyond isolated deliberative practices and institutions to examine their interdependence and interaction within a larger-scale deliberative system. So, for example, public meetings where criticism of party officials can be aired, public consultation, and deliberative experimentation can all be assessed in this broader light. Among the papers of this collection, the deliberative systems approach is developed most explicitly by Tang, which demonstrates how the idea can be applied fruitfully in China, although it is implicit in the paper by Korolev, which has an eye on the way the political system as a whole is changing.

Second, this special issue will respond to the widely identified need for more inclusive deliberative forums in China. Thus papers in this special issue will address not just structured deliberative forums led by government, but also more inclusive and informal deliberative gatherings among multiple actors and institutions. The coverage will range from designed forums in village democracy (in the paper by $\mathrm{He}$ ) to public hearings (the paper by Ergenc) to networks of activists (the paper by Han) to the internet (papers by Han and Tang), to national policy making processes (the paper by Korolev). The diverse participant groups include decision-makers, experts, representatives of civil society organizations, and lay citizens.

Third, this special issue will provide resources for a response to critics of the application of deliberative and participatory thinking in China, with reference to these new developments. If nothing else, the papers collected here show that deliberative and participatory innovation cannot be dismissed lightly, whatever its long-term systemic significance proves to be.

More specifically, the five papers in this special issue elaborate the mechanisms of deliberation and participation in the following ways.

Tang's paper offers a general discussion of the recent development of and prospects for deliberative democracy in China, with particular focus on the approach of a deliberative system. The paper is the first attempt to propose an analytical framework for the concept of deliberative capacity building in the context of contemporary China. Tang builds her discussions on three dimensions of deliberative capacity building, which suggest that deliberative capacity building offers a non-competitive approach to democracy in China by producing a stronger public sphere, more effective government responsiveness, and improved participatory competence.

He's paper explores deliberation and citizen participation from the perspective of village democracy in China. Built on an experiment of village deliberation, He's paper provides comprehensive details of how deliberative democracy experiments are designed and conducted in a Chinese village. Through roundtable talks, the experiment shows that deliberation helps to contribute - albeit in limited ways - to resolve conflicts regarding community affairs in the village. The paper is an excellent showcase for understanding the mechanisms, processes and forms of deliberative governance at the most local level of Chinese society.

Using China's new healthcare reform as an example, Korolev's paper explores how deliberative principles in China work at the national level. Drawing on existing empirical studies, Chinese-language reports and articles, official document analysis, 
and the author's fieldwork, the paper evaluates the extent to which deliberative democratic principles are present in the process of healthcare policy making, using five criteria of good deliberation. His findings suggest improvement of China's public policy-making process in terms of being more inclusive and pluralistic with the deliberation involved.

Han's paper analyzes non-state actors and their roles in practicing and promoting bottom-up deliberation. By using the case of a series of anti-dam campaigns conducted by environmental non-governmental organizations (ENGOs), her paper has shown that over the past decade Chinese civil society actors have increasingly exerted bottom-up pressure to attain a greater degree of deliberation, transparency, and accountability. By invoking the laws and policies that the government has recently introduced, ENGOs have formed their deliberation strategies to urge both the central and local governments to adopt more participatory and transparent policy making and examine the potential social and environmental impacts of large dams.

Focusing on local public hearing meetings, Ergenc's paper analyzes the most popular local-level deliberative practices in China. The paper focuses on the decisive role of the print media in this process of redefining the public hearing as a venue for citizen engagement. Through examining four categories of media workers involved with public hearings at the national and local levels, this paper suggests that while public hearings are used by the media in their call for increased political accountability, the media workers' active involvement in the public hearings more comprehensively defines the deliberative process.

\section{References}

1. Habermas, Jürgen. 1996. Between Facts and Norms: Contributions to a Discourse Theory of Law and Democracy. Cambridge: MIT Press.

2. Dryzek, John S. 2000. Deliberative Democracy and Beyond: Liberals, Critics, Contestations. Oxford: Oxford University Press.

3. Thompson, Dennis F. 2008. Deliberative Democratic Theory and Empirical Political Science. Annual Review of Political Science 11: 497-520.

4. Chambers, Simone. 2003. Deliberative Democratic Theory. Annual Review of Political Science 6: 307-326.

5. Leib, Ethan J., and Baogang He (eds.). 2006. The Search for Deliberative Democracy in China. Basingstoke: Palgrave Macmillan.

6. General Secretary of the Communist Party of China (CPC) Central Committee, Xi Jinping's address at the Third Plenary Session of the 18th CPC Central Committee in Beijing, 12 November 2013.

7. Shi, Tianjian. 1997. Political Participation in Beijing. Cambridge: Harvard University Press.

8. Nathan, Andrew J. 2003. Authoritarian resilience. Journal of Democracy 14: 6-17.

9. Chen, Jie. 2004. Popular Political Support in Urban China. Stanford: Stanford University Press.

10. Tang, Wenfang. 2005. Public Opinion and Political Change in China. Stanford: Stanford University Press.

11. Whyte, Martin King. 2010. Myth of the Social Volcano: Perceptions of Inequality and Distributive Injustice in Contemporary China. Stanford: Stanford University Press.

12. He, Baogang, and Mark E. Warren. 2011. Authoritarian deliberation: The deliberative turn in Chinese political development. Perspectives on Politics 9: 276-279.

13. Dryzek, John S. 2010. Foundations and Frontiers of Deliberative Governance, 139. Oxford: Oxford University Press.

14. Fishkin, James S., et al. 2010. Deliberative democracy in an unlikely place: Deliberative polling in China. British Journal of Political Science 40: 435-444.

15. Fishkin, James S., Baogang He, and Alice Siu. 2006. Public consultation through deliberation in China: The first Chinese deliberative poll. In The Search for Deliberative Democracy in China, ed. Ethan J. Leib and Baogang He, 229-244. Basingstoke: Palgrave Macmillan. 
16. He, Baogang. 2006. Participatory and deliberative institutions in China. In The Search for Deliberative Democracy in China, ed. Ethan J. Leib and Baogang He, 175-196. Basingstoke: Palgrave Macmillan.

17. He, Baogang, and Mark E. Warren. 2011. Authoritarian deliberation: The deliberative turn in Chinese political development. Perspectives on Politics 9: 283-284.

18. Archon Fung. Pragmatic Democratization: Preliminary reflections on Conceptions of Reform for nonLiberal Societies. Paper presented at the Annual Meeting of the American Political Science Association, Boston, 9.

19. Thompson, Dennis F. 2008. Deliberative democratic theory and empirical political science. Annual Review of Political Science 11: 15.

20. Mansbridge, Jane, et al. 2012. A systemic approach to deliberative democracy. In Deliberative Systems: Deliberative Democracy at the Large Scale, ed. John Parkinson and Jane Mansbridge, 1-26. Cambridge: Cambridge University Press.

21. Dryzek, John S. 2009. Democratization as deliberative capacity building. Comparative Political Studies 42: 1379-1402.

Beibei Tang is a Post-doctoral Fellow at College of Asia and the Pacific at The Australian National University. Her recent research focuses on deliberative governance and citizen participation in China, with a particular emphasis on the role of informal, unstructured deliberation in the public sphere in shaping urban grassroots governance.

John S. Dryzek is Centenary Professor in the ANZSOG Institute for Governance at the University of Canberra. He works on the theory and practice of democracy, and environmental governance. 